\title{
Sinonasal Alveolar Rhabdomyosarcoma in an Adult Patient: A Case Report and Review of the Literature
}

\author{
Ilson Sepulveda ${ }^{1}$, Paulo Vera ${ }^{2}$, Enrique Platin ${ }^{3}$, M Loreto Spencer $^{4}$, Vanessa Klaassen ${ }^{5}$, Cristina Hidalgo ${ }^{6}$, \\ Rodrigo Ascui ${ }^{7}$ and Joaquin Ulloa ${ }^{8}$ \\ ${ }^{1}$ Radiology Department, ENT-Head and Neck Surgery Service, General Hospital of Concepcion, Chile \\ ${ }^{2}$ RadiotherapyDepartment, Oncology Service, General Hospital of Concepcion, Chile \\ ${ }^{3}$ Oral and Maxillofacial Radiology Department, University of North Carolina School of Dentistry, Chapel Hill, USA \\ ${ }^{4}$ Pathology Department, General Hospital of Concepcion, Chile \\ ${ }^{5}$ Pathology Department, General Hospital of Concepcion, University of Concepcion School of Medicine, Concepcion, Chile \\ ${ }^{6}$ Ophthalmology Service, General Hospital of Concepcion, Chile \\ ${ }^{7}$ Oncology Service, General Hospital of Concepcion, Chile \\ ${ }^{8}$ ENT-Head and Neck Surgery Service, General Hospital of Concepcion, Chile
}

Submission: February 21, 2017; Published: March 14, 2017

"Correspondence Address: Ilson Sepúlveda, ENT-Head and Neck Surgery Service, General Hospital of Concepcion, Chile, San Martin Av. 1436, Concepcion, Chile, Email: isepulvedaguilar@gmail.com

\section{Abstract}

We report on a patient who presented to the ENT service with right side nasal obstruction. Imaging studies revealed an aggressive noncalcified solid heterogeneous mass centered in the right naso ethmoidal region. The mass was hyper enhanced following contrast media administration. The patient underwent partial tumor resection and a biopsy was performed confirming the presence of Solid Alveolar Rhabdomyosarcoma. The patient was treated with chemo-radiation therapy.

Keywords: CT; MRI; Ethmoidal; Rhabdomyosarcoma; Radio-Chemo Therapy

\section{Introduction}

Rhabdomyosarcoma (RMS) is a malignant tumor of striated muscle origin. It is derived from primitive mesenchyme that retained its capacity for skeletal muscle differentiation. It is one of most common sarcomas in newborns and childhood. Approximately $35 \%$ of RMS occur in the head and neck region. The combined use of chemo-radiotherapy and surgery improves survival rate significantly for up to 5 years.

\section{Clinical Case}

We report on a 22 years old insulin resistant female patient who presented to the Ear Nose and Throat (ENT) clinic with right side nasal obstruction. No history of epistaxis was reported but proptosis of the right eye was observed and loss of eyeball adduction. In the ipsilateral gonial region, hypoesthesia was present for two months duration. Lymphadenopathy of $4 \mathrm{~cm}$ in size was observed in the II A ipsilateral cervical ganglionic level. Computed Tomography (CT) and Magnetic Resonance Imaging (MRI) were performed.

The CT showed an aggressive non-calcified heterogeneous solid mass with a maximum diameter of $4.5 \times 4.5 \times 6.2 \mathrm{~cm}$, centered in the right nasal fossa and hyper enhanced following intravenous contrast media administration. The mass invades the right side of the frontal, maxillary, ethmoidal and sphenoid sinuses, hard palate, right orbit and alveolar bone. There was lymphadenopathy of the ipsilateral IB, II and V ganglionic levels. Evidence of intracranial invasion was no demonstrated (Figure 1).

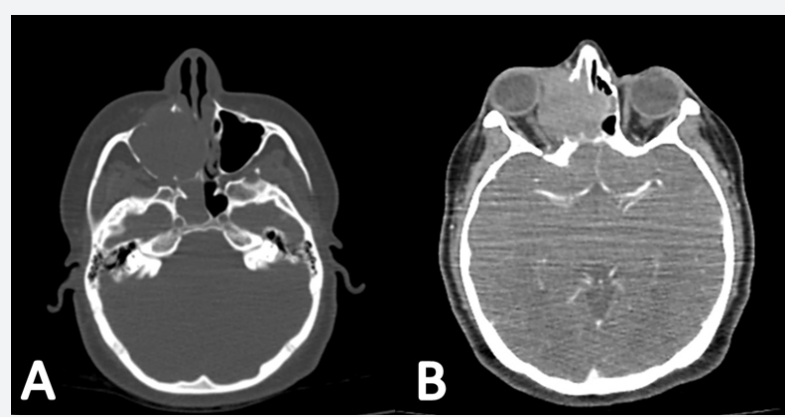

Figure 1: CT: A bone window axial plane, expansive process in ethmoidal and orbital region. B soft tissue window after contrast intravenous administration axial plane, showing high enhancement and invasion of the right maxillary sinus. 


\section{Cancer Therapy \& Oncology International Journal}

The MRI showed an isointense T2 solid mass centered in the right nasoethmoidal region invading the right side of the frontal sinus (Figures $2 \& 3$ ) The tumor is seen invading the right orbit with slight lateral displacement of the medial rectus muscle and globe (Figure 4). Intracranial invasion and hyper enhancement of the mass is seen in the post contrast fat saturated images (Figure 2).

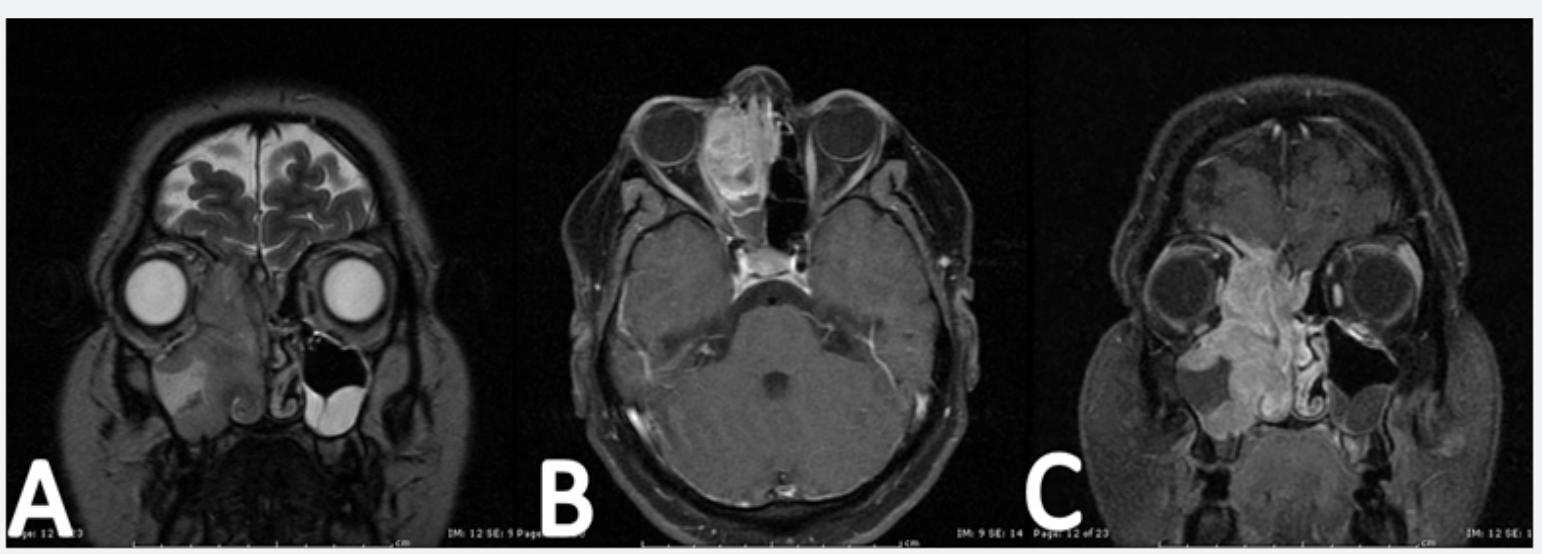

Figure 2: Magnetic Resonance (MRI) A. T2 sequence coronal plane showing isointense mass and mucous retention in left maxillary sinus. B T1 FAT SAT and Gadolinium axial plane, showing lateral displacement of the globe. C T1 FAT SAT and Gadolinium coronal plane, showing a heterogeneous process highly enhanced with intracranial invasion.

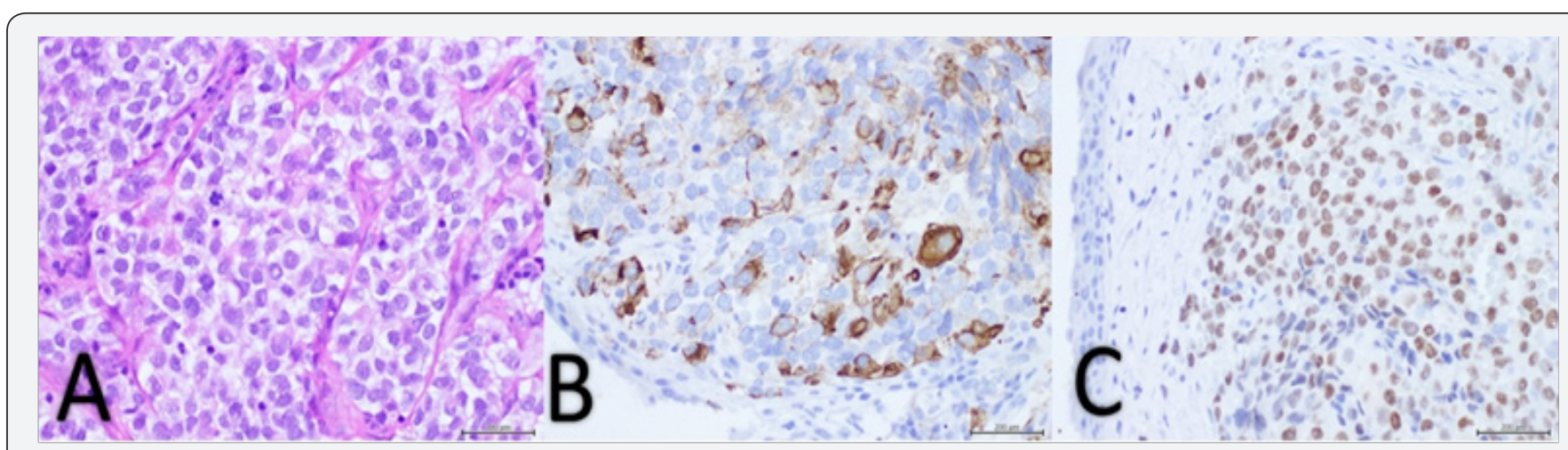

Figure 3: Inmunohistochemistry study (20x). A Hematoxylin and eosin stain. B Positive Actin stain. C Positive Myogenin stain.

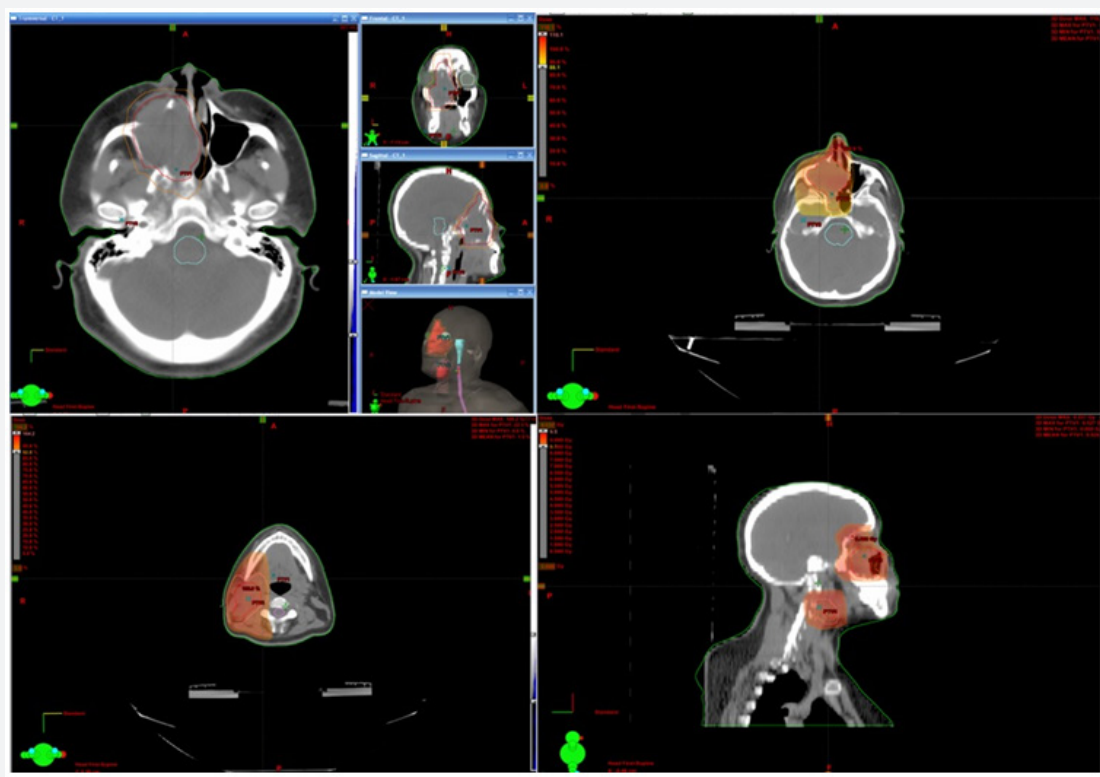

Figure 4: Three-dimensional conformal radiation plan. 


\section{Cancer Therapy \& Oncology International Journal}

Osseous Scintigraphy failed to reveal distant metastases and a bone marrow study of the right iliac crest did not show malignant cells. A biopsy was performed under general anesthesia showing a solid neoplasm that grew forming lobes, cells with large cytoplasm, oval nucleus with fine chromatin and small nucleolus. Immunohistochemistry tests were positive for Actin and Myogenin and confirmed muscle differentiation (Figure 3) negative for OCTV4, CD99, NSE, S-100, HMB45, EMA, Keratin AE1/3, Chromogranin and synaptophysin. Final pathology reported a "Solid alveolar rhabdomyosarcoma". Lymphovascular penetration was not observed.

The Head and Neck Tumor Board reviewed the patient's findings and the final diagnosis was determined to be Parameningeal Alveolar Rhabdomyosarcoma, (PAR) T3bN1M0. Chemo-radiation therapy was recommended.

Conventional radiotherapy consisted of a total dose of 54 Gy given over 7 weeks in 1.8 Gy increments (Figure 4). Following radiation therapy the patient was treated with chemotherapy consisting of a VAC regimen for 6 months: Vincristine each week and Dactinomicyn and cyclophosphamide + Mesna every 21 days.

Consequently, the patient developed Neovascular Glaucoma in the right eyeball from radiotherapy complication. This was treated with intracameral injection of Avastin, with no complications noted after procedure. A 2 year follow up MRI failed to reveal any ethmoid, maxillary or right nostril expansions. 3 years after treatment was completed, a follow up MRI exam showed recurrence of disease in right nasal nostril with intracranial invasion and lymphoadenopathy in IIA left ganglionic level (Figure 5). Following additional reviewed by the HNTB, palliative chemotherapy was recommended. He received 4 cycles of Ifosfamide and Etoposide with Mesna, showing regular tolerance and stabilization of nasal tumor. Upon finishing this article, 4 years after diagnosis, the patient remains in palliative care.

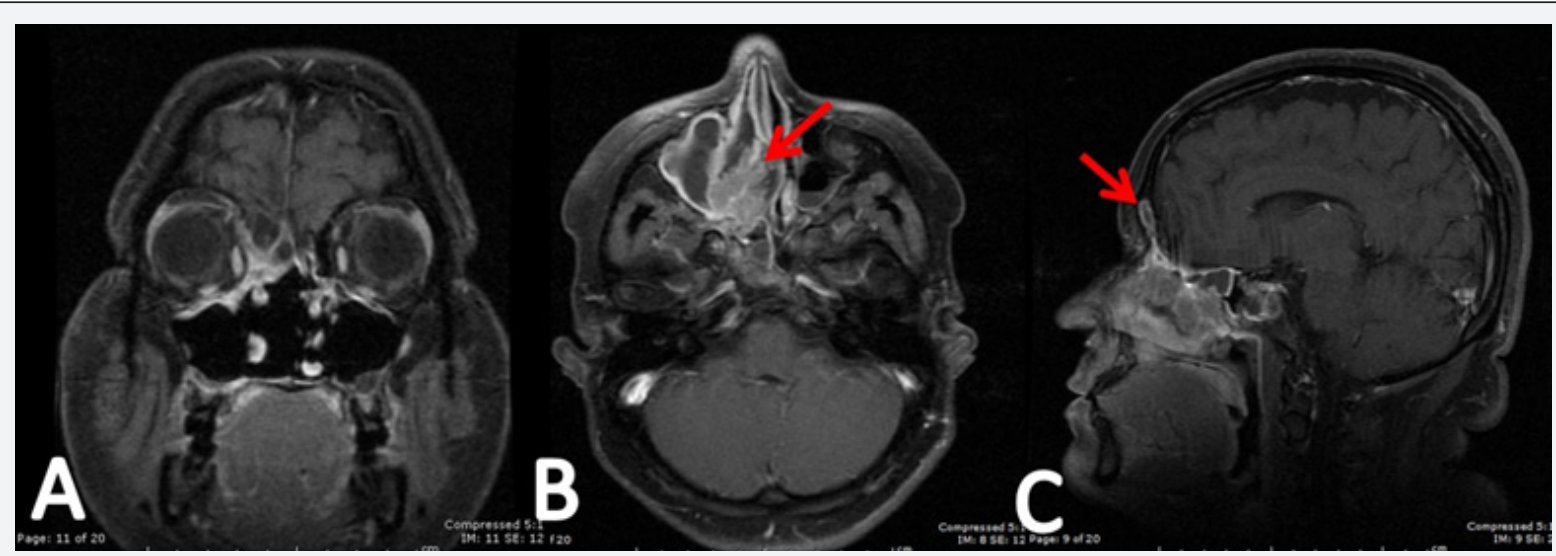

Figure 5: Magnetic Resonance (MRI) T1 sequence FAT SAT and Gadolinium. A Follow up 2 years do not showing evidence of residual or recurrent tumor. $\mathrm{B}$ and $\mathrm{C}$ follow up 3 years showing nasal recurrence and intracranial invasion (red arrows).

\section{Discussion}

RMS is a malignant tumor with striated muscle differentiation. It is derived from primitive mesenchyme that retained its capacity for skeletal muscle differentiation [1,2]. RMS was first described in the English literature in 1937 and in children in 1992. The tumor is mainly composed of bundles of cells with myogenic differentiation by immunohistochemical and ultra structural analysis. Rubin et al. described the first two examples of RMS with spindle cells in adults. Since then and until 2007, 21 cases have been described in the English literature [3].

This sarcoma is one of the most common soft tissues sarcomas in newborns, children, and young adults. [4] 20 to $25 \%$ of the cardiac neoplasms in adults are sarcomas [5]. The annual incidence of RMS in the USA is 4.6 per million in people under 20 years of age. RMS may occur in all age groups but is more prevalent in the first and second decades of life with a peak between 2 and 6 years of age, [6] It represents approximately $4-8 \%$ of all pediatric cancers [7]. Although tumors of head and neck are rare in children [8], approximately $60 \%$ of pediatric RMS cases occur in the head and neck [8-10].

RMS has different grades of striated muscle cell differentiation and it may occur in any part of the body. [9] Four different histopathological types have been described: embryonic, alveolar, pleomorphic and undifferentiated [6]. The two most common histopathological types described in childhood are embryonic and alveolar. [11] The embryonic type represents $70 \%$ of cases and it is mainly seen in children under the age of 12 and carries the best prognosis. The alveolar type occurs more frequently in the extremities affecting an older age group. It generally shows the chromosomal translocation ( $\mathrm{t} 2$ : 13; p35-14), carrying a more ominous prognosis than the other types of RMS [12]. The pleomorphic variety is less frequent and occurs more often in an older population [6].

Anatomically, RMS is classified as parameningeal, orbital and non-parameningeal non-orbital. Approximately 40\% of newly diagnosed RMS arises in the head and neck structures including 
parameningeal sites (16\% of all cases, and almost half of all head and neck cases), the orbit or eyelid ( $10 \%$ of all cases), and other non-orbit, non-parameningeal sites ( $10 \%$ of all cases). The parameningeal tumors carry the worst prognosis $[1,6]$.

The parameningeal sites include nose, nasopharynx, paranasal sinuses, middle ear, mastoid, infratemporal fossa and pterygopalatine fossa. Soderberg described the first case of an aggressive RMS in the middle ear. RMS of the temporal bone carries a poor prognosis due to its proximity to the brain and vital structures. A review of 20 cases from the literature by Jaffe et al. found a $0 \%$ two-year survival rate in [13]. The nonorbital and non-parameningeal forms include scalp, parotid gland, oropharynx, larynx and oral cavity. The tongue, palate and cheeks are the most common oral sites [6]. Of the $35 \%$ of RMS that occur in the head and neck, 10-12\% present in the oral cavity. RMS rarely occurs in the salivary glands. [14].

RMS can have a syndromic presentation such as their association with Beckwith-Wiedemann syndrome $(10 \%$ of cases) [13].

Metastasis occurs by hematogenous or lymphatic spread, most commonly to the lungs, bones and brain. [4] Prognosis is influenced by the anatomic location at the time of presentation, patient's age, completeness of resection, extent of metastatic disease and tumor histology [15].

A multidisciplinary treatment approach is most effective. In the last 30 years the combined use of chemoradiotherapy and surgery has significantly improved the survival rate of head and neck RMS rates to 5 years [6]. A study indicates that approximately $65 \%$ of children diagnosed with RMS will survive with combined therapy. [8] In the pediatric parameningeal RMS cases, the treatment of choice is chemoradiotherapy with surgery having a limited role due to the relative inaccessibility of the lesions and associated surgical morbidity [16].

Improved and innovative operative techniques of craniofacial surgical reconstruction have resulted in satisfactory functional and cosmetic results [8].

\section{Conclusion}

Rhabdomyosarcoma is a rare head and neck tumor in the adult population with poor prognosis despite aggressive therapy. Imaging studies play an important role in providing valuable information related to the involvement of critical anatomical organs.

\section{Reference}

1. Cristiane Miranda França, Eliana M M, Caran Maria Teresa S, Alves Adriana D, Barreto, et al. (2006) Rhabdomyosarcoma of the Oral
Tissues - two new cases and literature review. Med oral patol Oral cir bucal 11(2): 136-140.

2. Taketoshi Yasuda, Kyle D Perry, Marilu Nelson, Gnepp DR, Bridge JA, et al. (2009) Alveolar rhabdomyosarcoma of the head and neck region in older adults: genetic characterization and a review of the literature. Hum Pathol 40(3): 341-348.

3. V Goosens, Van den Berghe, C De Clercq, J Casselman (2008) Radiationinduced mandibular adult spindle cell rhabdomyosarcoma. Int J Oral Maxillofac Surg 37(4): 395-397.

4. Beatrice M J Neves, Paulo A de L Pontes, Eliana M Caran, Claudia Figueiredo, Luc LM Weckx et al. (2003) Head and neck rhabdomyosarcoma in childhood. Brazilian Journal of Otorhinolaryngology 69: 24-27

5. Smith IM, Anderson PJ, Yuen T, Tan E, David DJ (2008) Rhabdomyosarcoma of the mandible e long term management from childhood to adulthood. J Plast Reconstr Aesthet Surg 61(5): 582-585.

6. OA Fatusi, SO Ajike, SO Olateju, AT Adebayo, OO Gbolahan, et al. (2009) Clinico-epidemiological analysis of orofacial rhabdomyosarcoma in a Nigerian population". Int J Oral Maxillofac Surg 38(3): 256-260.

7. Shin Kariya, Patricia A, Schachern, Sebahattin Cureoglu, Michael M Paparella, et al. (2009) Histopathological temporal bone study of the metastatic rhabdomyosarcoma". Auris Nasus Larynx 36(2): 221-223.

8. Geok-Chin Tan, Mohd-Sidik Shiran, Abdul-Rahman Hayati, NoorAkmal Sharifah, Mohammad Rohaizak, et al. (2008) Alveolar Rhabdomyosarcoma of the Left Hand with Bilateral Breast Metastases in an Adolescent Female. J Chin Med Assoc 71(12): 639-642.

9. Rolf Sjuve Scott, Jaishree Jagirdar (2007) Right atrial botryoid rhabdomyosarcoma in an adult patient with recurrent pleomorphic rhabdomyosarcomas following doxorubicin therapy. Annals of Diagnostic Pathology 11(4): 274-276.

10. Daniela Dalfior, Albino Eccher, Stefano Gobbo, Dalla PP, Dvornik G, et al (2008) Primary pleomorphic rhabdomyosarcoma of the kidney in an adult. Annals of Diagnostic Pathology 12(4): 301-303.

11. Melanie Duval, Ricardo Faingold, Anne-Sophie Carret, Sam J Daniel (2008) Nasal ala rhabdomyosarcoma misdiagnosed as a facial infection. International Journal of Pediatric Otorhinolaryngology Extra 3(1): 44-47.

12. Elizabeth Charytonowicz, Carlos Cordon-Cardo, Igor Matushansky, Mel Ziman (2009) Alveolar rhabdomyosarcoma: Is the cell of origin a mesenchymal stem cell?" Cancer Letters 279 (2): 126-136.

13. Minoru Kuroiwa, Jun Sakamoto, Akira Shimada, Sotomatsu M, Hayashi $Y$, et al. (2009) Manifestation of alveolar rhabdomyosarcoma as primary cutaneous lesions in a neonate with Beckwith-Wiedemann syndrome. J Pediatr Surg 44(3): 31-35.

14. Janez Lamovec, Metka Volavšek (2009) Sclerosing rhabdomyosarcoma of the parotid gland in an adult: case report and review of the literature. Ann Diagn Pathol 13 (5): 334-338.

15. Cynthia Leaphart, David Rodeberg (2007) Pediatric surgical oncology: Management of rhabdomyosarcoma. Surgical Oncology 16(3):173185.

16. Sharad Chawla, Heather Tapp, Mark Schembri (2007) Para-meningeal rhabdomyosarcoma with critical airway compromise: Role of endoscopic debulking surgery. International Journal of Pediatric Otorhinolaryngology Extra 2 (4): 243-249. 
This work is licensed under Creative Commons Attribution 4.0 License

DOI: 10.19080/CTOIJ.2017.03.555619
Your next submission with Juniper Publishers will reach you the below assets

- Quality Editorial service

- Swift Peer Review

- Reprints availability

- E-prints Service

- Manuscript Podcast for convenient understanding

- Global attainment for your research

- Manuscript accessibility in different formats

( Pdf, E-pub, Full Text, Audio)

- Unceasing customer service

Track the below URL for one-step submission https://juniperpublishers.com/online-submission.php 